\title{
"I Am Who I Am": On the Perceived Threats to Personal Identity from Deep Brain Stimulation
}

\author{
Françoise Baylis
}

Received: 3 July 2011 / Accepted: 26 August 2011 /Published online: 14 September 2011

(C) The Author(s) 2011. This article is published with open access at Springerlink.com

\begin{abstract}
This article explores the notion of the dislocated self following deep brain stimulation (DBS) and concludes that when personal identity is understood in dynamic, narrative, and relational terms, the claim that DBS is a threat to personal identity is deeply problematic. While DBS may result in profound changes in behaviour, mood and cognition (characteristics closely linked to personality), it is not helpful to characterize DBS as threatening to personal identity insofar as this claim is either false, misdirected or trivially true. The claim is false insofar as it misunderstands the dynamic nature of identity formation. The claim is misdirected at DBS insofar as the real threat to personal identity is the discriminatory attitudes of others towards persons with motor and other disabilities. The claim is trivially true insofar as any dramatic event or experience integrated into one's identity-constituting narrative could then potentially be described as threatening. From the perspective of relational personal identity, when DBS dramatically disrupts the narrative flow, this disruption is best examined through the lens of agency. For illustrative purposes, the focus is on DBS for the treatment of Parkinson's disease.
\end{abstract}

F. Baylis $(\bowtie)$

Faculty of Medicine, Novel Tech Ethics,

Dalhousie University,

1379 Seymour Street, P.O. Box 15000, Halifax,

Nova Scotia, Canada B3H 4R2

e-mail: francoise.baylis@dal.ca
Keywords Neuroethics · Personal identity · Deep brain stimulation · Parkinson's disease · Agency

Ethics commentaries on the potential benefits and harms of deep brain stimulation (DBS) to treat patients with various advanced and treatment-refractory illnesses such as Parkinson's disease (PD), essential tremor, major depression, and obsessive compulsive disorder, often include a discussion of changes in personality and potential threats to personal identity (See, for example, [1-5]). In general, the authors of these commentaries recognize that disabling physical and psychiatric symptoms associated with illness can have a profound impact on behaviour, mood and cognition. Unique concerns are raised by some, however, when personality changes attributed to DBS are perceived as potential threats to personal identity.

For some commentators, concerns about DBS and threats to personal identity only arise when the personality changes are unwanted side-effects of DBS (e.g., mania). Indeed, when changes in personality resulting from DBS are positive (e.g., elevated mood), the discussion more obviously focuses on the promise of DBS. For others, concerns about threats to identity arise even when the personality changes are positive and consistent with therapeutic goals. In these instances, there are concerns about the fact of change, rather than the direction of change. Straddling these different perspectives on the promise and threat of DBS are testimonials from patients reporting "a 
feeling of strangeness and unfamiliarity with themselves after surgery ("I don't feel like myself anymore," "I haven't found myself again after the operation")" ([6], 1813).

This article explores the notion of the dislocated self following DBS using a relational account of personal identity [7]. For illustrative purposes, the focus is on DBS for the treatment of PD - a chronic progressive neuro-degenerative disorder. While DBS is currently in use (or under investigation) for many other disorders, this narrow focus is appropriate given world experience with DBS for PD.

The article begins with a cursory look (using patient narratives) at some of the benefits and harms of DBS when used to control the motor symptoms of PD. Next, a clear distinction is drawn between personality and personal identity, after which the basic features of a relational account of personal identity are presented [7]. This philosophical discussion introduces the concepts of projected and perceived self-narratives and explains their role in the cyclical and iterative process of identity formation involving "self"-perception, "self"-projection, "other"perception, and "other"-reaction. In turn, this discussion is followed by a critical review of excerpts from Helmut Dubiel's autobiographical narrative about life before and after PD, as well as life before and after DBS for PD [8].

Applying a relational account of personal identity, the article next reviews myriad plausible answers to the question "Is DBS for PD a threat to personal identity?" and concludes that while DBS may result in profound changes in behaviour, mood and cognition (characteristics closely linked to personality), there are problems with the claim that DBS is a threat to personal identity. This claim may be false, misdirected, or trivially true. The claim is false insofar as it misunderstands the dynamic nature of identity formation. The claim is misdirected at DBS insofar as the real threat to personal identity, when this is understood in relational terms, is the discriminatory attitudes of others towards persons with motor and other disabilities. And, from yet another perspective, the claim is trivially true insofar as any dramatic event or experience integrated into one's identity-constituting narrative could then potentially be described as threatening. From the perspective of relational personal identity, when DBS dramatically disrupts the narrative flow, this disruption is best examined through the lens of agency.

\section{DBS for PD}

PD is a chronic progressive brain disorder caused by a loss of dopamine-producing brain cells. PD leads to shaking (tremors), rigidity, difficulty with walking, slowness of movement, and impaired balance and coordination. In the later stages of illness, there can be cognitive problems, and in the advanced stages of illness, dementia is not uncommon.

At the present time, there is no cure for PD. The goal of treatment is symptom control, mainly involving the use of levodopa (a drug that converts in the brain into natural dopamine) and dopamine agonists. When the prescribed drug therapy is no longer effective in controlling the tremors and/or paucity of movement, and the drug induced dyskinesias are significant, another treatment option for some Parkinsonian patients is DBS. DBS can be effective in reducing tremors, slowness of movements, and gait problems, but there can be serious unwanted side-effects.

DBS involves implanting electrodes deep into the brain. The preferred surgical targets for PD are the subthalamic nucleus (STN) and the globus pallidus interna (GPi) - two brain areas involved in motor control. For patients with tremor-dominant PD, the target may be the thalamus. The electrodes are connected to a small battery-operated neurostimulator that is surgically implanted under the skin, usually in the upper part of the chest below the collarbone. The stimulator, which looks like a cardiac pacemaker and is sometimes referred to as a brain pacemaker, is externally programmed to deliver continuous electrical signals to the targeted brain area. The stimulation parameters - the amplitude, the frequency, and the pulse width - are set by the physician. With some devices, at the discretion of the programmer, the patient may control the amplitude (the voltage) within certain parameters (e.g., 2.4-3.2 V).

The potential benefits of DBS for the treatment of patients with advanced PD are documented in narrative form in testimonials available on Medtronics ${ }^{1}$ websites and in case reports. Consider, for example, Richard's narrative on Medtronics' Australian website:

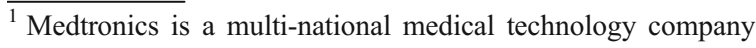
that manufactures DBS stimulators.
} 
"When you are an actor, your body is a tool. If your tool is broken, you can't work. You can't earn a living and you can't express yourself." "My left arm wouldn't cooperate, so I'd put it in my pocket, or hold it. Sometimes it would just dangle there. The comedy I had been enjoying so much wasn't so fun anymore." "I was always going to another doctor, going to another specialist, having another test or procedure. It felt like all I did was live in waiting rooms and walk down endless corridors without ever getting anywhere." Eventually, his [Richard's] research led him to deep brain stimulation and he decided to go ahead. "I'd made up my mind; done all the tests, had the haircut and passed the audition." The day of the operation wasn't easy... "Then when they turned the stimulator on the stiffness disappeared. The effect was immediate." "Now I stand up with ease, where once it had been an almighty struggle. I cross the room like any normal person going for a stroll" [9].

Similar personal stories can be found on Medtronics' American website. Below is an excerpt from Chris' story:

Chris noticed something wrong when he was out walking with one of his three daughters. "My arm swing on my right side just quit," he recalled. "I started dragging my foot. I had no idea what was happening." Within a year of being diagnosed he lost the use of his right hand, which meant he couldn't write. He also developed slowness and rigidity, cramping, and involuntary head movements. "My life basically became just work and sleep." On his first morning back at work loading trucks [after the surgery], Chris felt like a new person. "I could tell that I wasn't going through the normal problems in the morning," he says. "It usually would take an hour and a half of cramping and walking weirdly. That was mostly just gone. I developed a lot more confidence at work" [10].

Less well documented, but no less relevant, are the common physical and psychological side-effects of DBS experienced by patients with PD. For example, there is the potential problem of weight gain, as well as the potential for serious disruptive changes in behaviour, mood and cognition. These changes can include speech dysfunction (impaired fluency and vocabulary), reduced working memory and process- ing speed, acute depression, pathological crying, mania, fear and alienation. If we return to Richard's story (excerpted above), it is not all happiness and light. Richard experiences depression and slurred speech:

While the operation was a success, a few weeks later, Richard went through a period of depression... "The ordeal of the operation was so profound that a sense of anticlimax began to hover over me." "Back home in the suburbs you're a normal bloke, but you feel like you've been to another planet." Richard is having to write now rather than act, because he's suffering from a side-effect of the operation known as dysarthria or slurred speech. He finds that his speech therapy is like going back to acting classes - think loud and speak slow [9].

A more dramatic case of untoward consequences, originally reported by Leentjens and colleagues [11], and subsequently referred to by many others, involves a 62-year-old male patient with PD who is admitted to a psychiatric hospital for a manic state resulting from DBS. As reported by Walter Glannon:

A mood stabiliser failed to control his symptoms, which included megalomania and chaotic behaviour that resulted in serious financial debts. He became mentally incompetent. Adjustment of the stimulator resolved the mania and restored his cognitive capacity for insight and rational judgment. Yet this resulted in a return of his motor symptoms, which were so severe that the patient became bedridden. This left the patient and his healthcare providers with a choice between two mutually exclusive options: to admit the patient to a nursing home because of a serious physical disability, despite intact cognitive and affective capacities; or to admit the patient to a chronic psychiatric ward because of a manic state, despite restoration of good motor function ([1], p. 290).

While competent (that is, off DBS), the patient was presented with these options. He chose DBS to improve his motor function, understanding that the resulting mania would result in his institutionalization in a chronic psychiatric ward.

Clearly, patients with PD who undergo DBS can (and do) experience significant benefits. These same patients, however, also can (and do) experience 
significant unwanted side-effects including cognitive and psychiatric disturbances (such as major depression and mania). Whether the effects of DBS are positive or negative, physical or psychological, transient or permanent, they can have a profound impact on personality, on familial, marital, social, and professional relations, as well as occupational functioning. For those who embrace a static view of personal identity as comprised of core inclinations and character traits, changes in these domains arguably represent a serious threat to personal identity. For others, who embrace a dynamic view of personal identity and consider the notion of an authentic self "given by nature and unchanged by time" outdated [12], changes in these domains do not represent a threat to personal identity, but rather are constitutive of personal identity.

Below, I introduce a philosophical account of relational personal identity as a dynamic interpersonal activity based in narrative. On this view, personal identity is not tied to an individual's core inclinations or character traits, but reflects an individual's lived experience (and perhaps some measure of introspection) as integrated into her autobiographical narrative.

\section{A Relational Account of Personal Identity}

Personal identity is a concept we rely on in attributing moral responsibility to one person rather than another, and in ensuring that persons get their just desserts. Marya Schechtman makes this point succinctly when she writes of personal identity that it "serves as a minimum condition in the assessment of responsibility, obligation, and certain sorts of entitlement. Our practices of promising, contracting and assessing praise or blame depend on this notion" ([4], p. 68). In sharp contrast, our practices of promising, contracting and assessing praise or blame in no way depend upon personality. For example, if I thought you were a kind and considerate person when I made you a promise, I can't simply disregard my promise to you because, in my estimation, you are no longer the kind and considerate person I once thought you were. Similarly, if I contract with you to pay you an hourly wage to build me a fence, I can't simply default on any payment owed to you because you have become apathetic since your partner ran off with a younger man. If you are an imprisoned murderer who has experienced a religious conversion so that you are now a pacifist who abhors violence, you are not thereby absolved of responsibility for your prior criminal behavior.

In all of these hypothetical situations your personality may have changed, and the change may be sufficiently radical as to prompt others to say of you that you are a different person. But in important respects such statements would be for rhetorical effect. Generally, it would be understood that, notwithstanding any change(s) in personality, you are nonetheless the person to whom a promise, a wage or a punishment is owed. By the same token, barring specific terms suggesting otherwise, neither the promise, the wage nor the punishment is owed to another in your stead. In brief, a change in personality, whether gradual or abrupt, subtle or radical, temporary or permanent, does not in and of itself make for a change in personal identity. ${ }^{2}$ The two conceptspersonality and personal identity-are not synonymous.

How then are we to define personal identity? A highly influential answer to this question can be found in Schechtman's book The Constitution of Selves. In this book, Schechtman helpfully draws our attention to the pivotal identity question - which she dubs the characterization question-which is "what actions, experiences, beliefs, values, desires, character traits and so on (hereafter abbreviated 'characteristics') make a person who she is" ([13], p. 73)? In exploring this question, Schechtman argues that "a person creates his identity by forming an autobiographical narrative - a story of his life" ([13], p. 93). According to Schechtman:

[I]ndividuals constitute themselves as persons by coming to think of themselves as persisting subjects who have had experience in the past and will continue to have experience in the future, taking certain experiences as theirs... A person's identity ... is constituted by the content of her self-narrative, and the traits, actions, and experiences included in it are, by virtue of that inclusion, hers ([13], p. 94).

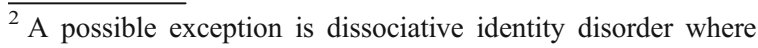
two or more personalities appear to control an individual's behavior (as evidenced by radical psychological discontinuities). Schechtman suggests that perhaps the different personalities "represent distinct persons inhabiting a single human body" ([4], 67).
} 
Not all personal narratives are identity-constituting, however. Some such narratives are at most personal myths. According to Schechtman, for a self-narrative to be identity-constituting, it must satisfy two constraints - the articulation constraint and the reality constraint. An identity-constituting self-narrative must be capable of local articulation (that is, the person must be able to provide some account of her history, her life situation, and her motivations). As Schechtman insists, "the narrator should be able to explain why he does what he does, believes what he believes, and feels what he feels" ([13], p. 114). A person need not be able to narrate her whole life in a self-conscious way, but she must be able to narrate parts of it ([13], p.105). That is, she must be able to render her self-narrative intelligible. As regards the reality constraint, Schechtman insists that the self-narrative must cohere with basic observational facts about the world. That is, an identity-constituting selfnarrative must cohere with reality: "This is not to say that a narrative must be totally accurate in every regard or contain no trivial mistakes, but it should exhibit a fundamental grasp of what the world is like" ([13], p. 83).

From another perspective, Laurence Thomas argues that identity is an interpersonal social construct. He writes:

[W]e are constituted through others, ... the way in which we conceive of ourselves, at least in part, owes, much to how others conceive [of] us, and this is necessarily so. The way in which we think of ourselves is inextricably tied to the way in which others think of us ([14], p. 365).

This view is consonant with the views of those who espouse a feminist relational understanding of autonomy. As Susan Sherwin reminds us:

$[\mathrm{N}] \mathrm{o}$ one is fully independent ... the view of individuals as isolated social units is not only false but impoverished: much of who we are and what we value is rooted in our relationships and affinities with others ... all persons are, to a significant degree, socially constructed ([15], pp. 34-35).

Finally, it is also important to recognize the ways in which the body can and does influence who we are and how we can be in the world. Race, class, gender, ethnicity, age, sexual orientation, and ability are features of the self that others read off the body in the context of "complex networks of social norms, institutions, practices, conventions, expectations, and attitudes" ([16], p. 15). So it is that "agents' identities are formed within the context of social relationships and shaped by a complex of intersecting social determinants, such as race, class, gender and ethnicity" ([17], p. 4). Reasoning along similar lines, Linda Martín Alcoff writes more specifically about how race and gender affect "our relations in the world, which in turn affects our interior life, that is, our lived experience or subjectivity" ([18], p. 92).

Taken together, these discrete perspectives on identity inform my philosophical account of relational identity as "a dynamic, socially, culturally, politically, and historically situated communicative activity (based in narrative and performance) that is informed by the interests, perspectives, and creative intentions of close and distant others" ([7], p. 110). This account of relational identity takes seriously the claim that "a person creates his identity by forming an autobiographical narrative-a story of his life" ([13], p. 93). It also embraces the claim that we are constituted/ constructed in and through personal (intimate) relationships and public (impersonal social and political) interactions. Finally, it accepts the claim that we are embodied selves situated in particular social, cultural, political and historical contexts. In this way, relational personal identity recognizes that the desires, beliefs, values, emotions, intentions, memories, actions and experiences that make up a person's self-narrative are shaped in and through relationships.

This relational account of personal identity is distinct from both the somatic (or biological) account of personal identity, as well as the psychological account of personal identity. My identity is not in my body or in my brain, but in the negotiated spaces between my body and brain, and the bodies and brains of others:

[I]dentities are created by relational beings mutually engaged in the never-ending project of constituting themselves in and through personal relationships and public interactions in order to answer such personal questions as: Who am I? Where am I from? Where have I been? Where am I going? What do I care about? What do I stand for? Who do I want to be? Who am I becoming? Indeed, it is through our (more 
or less conscious) interpretations of our values, memories, actions, experiences, and so on as well as the (more or less conscious) interpretations of these same characteristics by others that we come to embody answers to these pivotal questions, thereby instantiating our place in the world as we continually strive for balance between how we see and understand ourselves and how others see and understand us ([7], p.117).

Relational identity is a dialectical process aimed at achieving equilibrium - some kind of temporary and temporizing balance between self-ascription and ascription by others (i.e., others who are a part of one's familial, social, cultural, and political clusters of meaning and belonging) [7]. This view is consonant with the work of Lorraine Code who suggests that "uniqueness, creativity, and moral accountability grow out of interdependence and continually turn back to it for affirmation and continuation" ([19], p. 82). With a relational account of personal identity, the identityconstituting narrative is the narrative that effectively balances how a person sees and understands herself, with how others see and understand her. That is, the identity-constituting narrative is the narrative that satisfies the "equilibrium constraint".

The equilibrium constraint requires minimal endorsement or uptake by others of one's projected selfnarrative. When there is no uptake, the cyclical and iterative process of identity formation that involves combining and resolving projected and perceived selfnarratives into a coherent, identity-constituting narrative begins (again).

To be clear, equilibrium is different from stability, insofar as the latter is presumed to be more enduring. Equilibrium, on the other hand, is a temporary state of affairs during which time the projected self-narratives and perceived self-narratives are in balance. At such time, the self is able to take notice of her place in the world and choose to embrace, refine or revise her projected self-narrative as part of the ongoing, neverending process of identity formation.

A projected self-narrative can be a preferred selfnarrative or performed self-narrative and most likely is some combination of both. The preferred selfnarrative is the story of who the person wants to be. If we think back to the cases described at the outset, Richard's preferred self-narrative might be that of the brilliant actor struck down in his prime by illness. If others perceive Richard in this way then they will endorse his story, and for a time this will be his identity-constituting narrative. If this is not how others perceive Richard, however, then the equilibrium constraint will not be satisfied. Others, for example, might consider Richard an average actor, but an excellent writer who might never have discovered his talent for writing, but for his illness.

In tandem with the preferred self-narrative is the performed self-narrative. The performed self-narrative is the story of who the person can be, given the ways in which his life is constrained by self and others. Richard's performed self-narrative may be that of the self-assured curmudgeon who writes for a living, because that is what brilliant actors do when they retire. But maybe Richard fears his illness and chooses to mask his fear with cocky, surly behaviour.

Who is Richard? If we look for an intelligible selfnarrative articulated by Richard and facts that cohere with reality, as Schechtman would have us do, Richard is a man who once worked as an actor, and whose acting career has come to an end because of PD. Can we say more? For example, can we say that Richard was a brilliant actor; is an acerbic character?

On a relational account of personal identity, Richard is the person at the intersection of who he wants to be, and who others will minimally let him be. From a more technical standpoint, Richard's identity-constituting narrative is the self-narrative that satisfies the equilibrium constraint. That is, Richard's identity-constituting narrative is the narrative that he is able to construct and maintain through complex (conscious or unconscious) intimate and public interactions involving "self"-perception, "self"-projection, "other"-perception, and "other"-reaction.

For Richard, the fact that he worked as an actor, may be sufficient minimal uptake of his self-narrative to satisfy the equilibrium constraint. Then again, Richard may need further endorsement of additional features of his self-narrative to effectively balance how he sees and understands himself with how others see and understand him. This endorsement may come in the form of laudatory reviews praising Richard's performances. If there are no such external endorsements, however, and instead Richard is faced with an alternative narrative of 'average actor', a number of strategies are available to Richard in an effort to establish equilibrium. For example, Richard could 
modify his "self"-perception and "self"-projection to better accommodate the perceptions and reactions of others in his community of belonging. For example, Richard may come to see and understand himself as others see and understand him - a talented writer who has found his calling. As a result, Richard may (consciously or unconsciously) come to have less care about his previous career as an actor and may have less vested in the persona of 'brilliant actor'. As a result of this change in perception, Richard may change his projected self-narrative and in so doing garner sufficient uptake of his revised narrative for there to be equilibrium. On the other hand, if neither the original self-narrative nor any revised selfnarrative garners minimal support/endorsement, then another option for restoring equilibrium would be for Richard to change his community of belonging. Then again, Richard could attempt to achieve equilibrium by simply dismissing any discordance between his projected narrative and the narrative perceived by others, as their error.

With the equilibrium constraint, what matters for Richard's identity-constituting narrative is not what others objectively believe to be true (as these others could be "mistaken, bigoted or hostile" ([20], p. 92)), nor what Richard asserts to be true (as he may be "ignorant, mistaken, self-deceived, or mendacious" with respect to his self-narrative ([7], p. 116)), but what balance can be achieved between who Richard says he is, and who others will minimally let him be. On a relational account of personal identity, Richard's identity-constituting narrative is what emerges in the negotiated space between Richard and others. Richard's identity is a balance between self-ascription and ascription by others ("self"-perception, "self"projection, "other"-perception, and "other"-reaction) as he (consciously or unconsciously) engages in the neverending dialectical project of tailoring his identity (or shifting his community of belonging) in response to events, experiences and perceptions.

\section{Helmut Dubiel}

I met Helmut Dubiel, philosopher, university professor, and author of Deep in the brain: Living with Parkinson's disease [8] in April 2009. We were both invited speakers at a conference in Freiburg, Germany entitled Pimp Your Brain! [21] I spoke in English about the ethical and social implications of neuroenhancement. Dubiel spoke in German about his illness experience with PD and with DBS. I don't understand or speak German and so after his talk we met for coffee. Dubiel is fluent in English.

Dubiel was diagnosed with early onset PD at the age of 46. When I met him he had been living with PD for close to 16 years and had been fitted with his brain pacemaker for about three years. As a sideeffect of DBS, Dubiel's speech was impaired. In order to enunciate clearly, he needed to turn off the pacemaker or set the amplitude very low. When the amplitude was high, his voice was low and his articulation was slurred. In his words, his speech was soft and "washed out" ([8], p. 116).

In conversation with Dubiel, I learned about some of the early problems he experienced while teaching. There were difficulties writing on the chalk board, speaking clearly and commanding the respect of students. As I listened to Dubiel, I reflected on how important it is for those of us who lecture in front of small and large classes to have control of our mobility and our speech. Dubiel also alluded to his academic successes and how he had imagined (hoped) his writings would be remembered as important contributions to the literature. While he was pleased with the critical acclaim for his autobiography, he also bemoaned the fact that he likely would be remembered more for this work than his academic writing.

When I asked Dubiel more pointed questions about identity, he spoke about the importance of erotic touching and how with PD it had become more difficult for him to see himself, and for others to see him, in the role of lover. Of the early days following diagnosis, Dubiel reports that "[e]rotic touching and encounters grew all the more important the thicker the glass wall became between me and my social environment" ([8], p. 39).

Near the end of our conversation, Dubiel needed to neuro-stimulate himself. This prompted me to ask him if he was self-conscious doing this in a public place, and whether it would be better if the neuro-stimulator could be placed under the skin near the wrist instead of in the upper part of the chest and if it could be activated by applying gentle pressure. I suggested this might allow for more discrete neuro-stimulation. On this point Dubiel was adamant- "No, then I would feel like a machine". 
At the end of our conversation, Dubiel told me that his autobiography would soon be available in English. In reading this book, I learned more about Dubiel the professor, the lover, the father, the son and the friend. In each of these roles, Dubiel's life had transitioned in challenging ways. Of particular note were the ways in which the diagnosis of PD and the treatments available to him (including DBS) shaped his sense of self in and through his relationships with others.

Early in his autobiography, Dubiel reports on his diagnosis of PD:

The first and simultaneously most lasting feeling that the diagnosis of Parkinson's triggered was a sense of narcissistic injury, one that no other injury inflicted by a human being has ever surpassed. At a single blow, I felt excluded from the fellowship of those who simply had their bodies at their disposal, who experienced no friction losses between an impulse to act and the action itself ([8], pp. 38-39).

This is a clear statement in explicitly relational terms about how PD had a profound impact on Dubiel's personal identity in excluding him from the fellowship of able-bodied individuals. As noted above, persons are embodied selves. So it is that Dubiel's body is a constitutive element of his self; it influences who he is and how he can be in the world. How he sees and understands himself, and how others see and understand him is mediated through his body and, more particularly, his limited ability to control his body. This limited ability is a recurring theme in Dubiel's autobiography.

Dubiel dislikes photos of himself. They do not allow him to see himself as he would like to be: "virile and in full control of my life, a man who lifts his eyes to the stars but has both feet on the ground" ([8], p. 38). In the few photos of Dubiel taken during his first years with PD, Dubiel notices "a mask-like rigidity, while in contrast I find my eyes to be larger, sadder, and more expressive than before I fell ill” ([8], p. 39).

At the time of diagnosis, Dubiel is, from his perspective, at the top of his game:

I had just been appointed a full professor, while retaining my position as deputy director of a small but prestigious research institute. At the time, my ambition and energy level were ample for two jobs. I was successful. I was publishing books and monographs on a regular basis, and they found readers... I was the crown prince of the institute ([8], p. 50).

Once I received the diagnosis, however, a gradual process of alienation arose between the institute and me, which would conclude three years later with a humiliating dismissal ([8], p. 50).

Here the theme of alienation is even more explicit and continues to be so for Dubiel as his illness progresses. In the year following his diagnosis, he reports:

I changed radically. It was surely not a transformation caused by verifiable changes in brain physiology, but rather a psychological adjustment to a biorhythm that had becomes utterly unpredictable due to the illness and medication ([8], p.50) ... I became estranged from many colleagues and friends whom I had known for ages [8], (p. 52).

In further contemplating his illness, Dubiel writes:

[W]hen it [Parkinson's] is full-blown, [it] robs a person of the ability to continually reinvent himself. It forces him into a cramped cycle of ever-identical activities ... One's life becomes similar to that of a plant: silent, without transcendence and autonomy. In a sense, it's not even a life anymore-just existence in an atrophied form ([8], p. 60).

At the time of writing Dubiel does not have fullblown PD. Atrophied existence is what he anticipates, not what he experiences. Dubiel's experience is one of fragmentation - of living at least two lives - a private life in which he partially acknowledges his illness to himself and a close circle of friends, and a public life in which the illness is a well-guarded secret.

Eventually, the drug therapy is no longer effective in counteracting the symptoms of Dubiel's disease and the dyskenesias caused by over-medication have become "torturous". At this time, Dubiel opts for DBS in the hope of improving his motor functions. Post-surgery he reports that from a medical perspective all went well:

According to the surgeons' criteria, the operation was a full success. My tremor disappeared, as well as the dyskenesias which had tormented 
me... My movements were fluid and relaxed. My medication intake could be drastically reduced ([8], p. 84).

Dubiel acknowledges these facts. He admits that the "tremor, the torturous dyskenesias, and the 'off' conditions were simply gone. [The] medication intake had dropped by twenty-five percent, [and] overall mobility and endurance were markedly better than before" ([8], p. 94). Nonetheless, similar to the experience of other patients with PD who have undergone DBS, Dubiel is "dissatisfied with the overall outcome of the procedure" ([8], p. 93):

... in my case the operation had merely replaced the plague with cholera. I simply had the impression that during the entire first year the upshot of this major and extremely expensive surgery had been to replace one set of grave symptoms with another ([8], p. 93).

Dubiel experiences profound depression and a range of physical problems including a speech disturbance, shortness of breath when bending, inability to write, small-stepped gait and a tendency to fall on stairs and no sense of smell and taste. Dubiel identifies his speech problem as the worst of these side-effects:

My worst post-operative symptom, which remains unchanged to this day, is a speech disturbance: my volume is too low, and my articulation is poor, slurred. Often I can't even command twenty percent of my normal speech volume ([8], p. 94).

While Dubiel describes his worst side-effect as reduced speech volume, in relational terms, his worst side-effect is a profound sense of alienation. For Dubiel, the volume of this voice (and more particularly the risk of "making unintelligible, poorly articulated comments in a feeble voice" ([8], p. 123)) mark him in public and set him apart from his peers. Another source of stigmatization is his movement patterns: "Now I walk through the street and count the oncoming pedestrians who look at my asymmetrical shuffling gait with curiosity or alienation" ([8], p. 109). These physical limitations negatively affect Dubiel's relationships with close and distant others.

In time, Dubiel learns to deal with the unwanted side-effects by adjusting the pacemaker amplitudes. If he wants to enunciate clearly, he sets the amplitude very low knowing this will lead "to relative immobility and depression" ([8], p. 120). In the alternative, if he wants to walk any distance, he sets the amplitude much higher knowing that his speech will become inaudible. While having to choose between talking and walking is less than ideal, Dubiel's restored ability (within limited parameters) to control his body in social situations restores his pride and professional authority. In turn, this allows him to conceive of a continued place for himself within the academy. Meanwhile, he dreams about the things he would like to be able to do including, "walk through large crowds of people without fear, dance, talk with strangers in noisy train stations, stroll along the path that leads from Harlem down to Battery Park on a sunny September day in New York" ([8], p. 128).

So, who is Helmut Dubiel? Dubiel is the person at the intersection of who he wants to be, and who others will minimally let him be. His identityconstituting narrative is the self-narrative that satisfies the equilibrium constraint. It is the narrative that he is able to construct and maintain through complex (conscious or unconscious) intimate and public interactions involving "self"perception, "self"-projection, “other"-perception, and "other"-reaction. From Dubiel's autobiographical narrative we know that at least during one period of equilibrium following DBS, he was a person alienated from colleagues and loved ones.

\section{DBS for PD and Threats to Personal Identity}

Is DBS for PD a threat to personal identity? This question can be answered in the affirmative or the negative depending upon the theory of personal identity that informs the answer. For example, applying the narrative self-constitution view of identity, Schechtman concludes that DBS for PD can be a threat to personal identity [4]. Schechtman elucidates this viewpoint in her discussion of a hypothetical case involving a Mr. Garrison, a 61-year-old American with PD who consents to DBS to treat his tremors and severe apathy. Following surgery, Mr. Garrison experiences significant improvement in his motor symptoms and dramatic changes in personality. Where once he was shy and introverted, he is now outgoing and gregarious. Where 
once he was a loyal Republican, he is now a Democrat. Where once he was enthusiastic about his work, he has now quit his job to promote various social, political and charitable causes.

Schechtman believes that "since narrative is a dynamic notion, continuity of narrative is thoroughly compatible with even quite radical change" ([22], p. 140). Nonetheless, she concludes that DBS can be a threat to personal identity. In her discussion of Mr. Garrison's personal identity Schechtman is particularly concerned with the mechanism of personality change-electrodes implanted in the brain, not "natural personal development" ([4], p. 85). The 'fact' that Mr. Garrison's values, motivations and actions are the result of DBS is, according to Schechtman, at odds with the articulation constraint on identity-constituting narratives according to which "the narrator should be able to explain why he does what he does, believes what he believes, and feels what he feels" ([13], p. 114). Mr. Garrison can't explain how his actions flow from his "plans, projects, intentions, beliefs, and desires" because they don't; "his current passions and interests - the things he takes as reasons-were caused by manipulation of his brain" ([4], p. 85). From this perspective, Mr. Garrison's personal identity is threatened insofar as he runs afoul of the articulation constraint. From another perspective, Schechtman insists that if Mr. Garrison were to suggest that his newfound passions and interests were the result of personal development and not DBS, then he would run afoul of the reality constraint, according to which the self-narrative must cohere with basic observational facts about the world.

Schechtman's affirmative answer to the question "Is DBS a threat to personal identity?" is intuitively appealing. "But for" the DBS, Mr. Garrison would still be the shy Republican with a Puritan work ethic. To appreciate the limitations of this affirmative response, however, we need only reflect briefly on the use of DBS to treat psychological problems instead of motor symptoms. Consider, for example, the use of DBS for the treatment of severe, treatmentrefractory depression or obsessive compulsive disorder. Imagine that following DBS the depressed patient is happy or the patient with obsessive compulsive disorder doesn't experience the same impulses. Would we find the conclusion that DBS is threatening to personal identity as intuitively appealing in these instances? Or, would we be more inclined to endorse the view that "even quite radical change" can be successfully integrated into a patient's autobiographical narrative (i.e., her life story)? Further, if we return to Schechtman's original description of the articulation constraint on identity-constituting narratives - that the person be able to provide some account of her history, her life situation, and her motivations; that she be able to narrate parts of her life in a self-conscious way; that she be able to render her self-narrative intelligible-it is unclear why a patient could not satisfy the articulation constraint by including a description of consent to DBS in her self-narrative.

In my view, Schechtman's intuitively appealing affirmative answer to the question "Is DBS for PD a threat to personal identity?" is unsatisfactory. Below, applying a relational account of personal identity, I offer alternative responses to the question "Is DBS for PD a threat to personal identity?"

A first plausible response to this question affirms that DBS for PD is not (and never could be) a threat to personal identity because personal identity is a dynamic concept:

[t]here is no true self, only a dynamic socially, culturally, and politically constituted self that is historically situated and that at any one point in time can be more or less stable. Indeed, it is only in interaction with others and through their instantiation of, or resistance to, a storied and projected self that a person can experience either affirmation or disruption, both of which are relevant to the project of stabilizing one's selfnarrative in an effort to achieve a period of equilibrium ([7], p. 123).

A patient with PD who undergoes DBS may experience "a unique form of biographical disruption" ([23], p. 1850). It does not follow, however, that the patient's personal identity is under threat. If the self is a dynamic, socially, culturally and politically constituted self that is shaped over time through experience (and perhaps introspection), it makes no sense to describe any particular event or experience (including DBS) as threatening. There is no pre-set autobiographical narrative (i.e., life story) that has been thwarted by some unfortunate event or experience. There just is the life story as it unfolds. On this view, what matters is whether (and, if so, to what extent) an 
event or experience is integrated (consciously or unconsciously) into an identity-constituting narrative.

This brings us to a second plausible response to the question "Is DBS for PD a threat to personal identity?" This response involves looking at the question from a moral perspective, and seeing that an identity-constituting narrative can be damaging when it is the result of oppression, as "when an individual in certain contexts and circumstances is forced to live for periods of time within the confines of another's ideas about what makes for an appropriate self-narrative" ([7], p. 124). As I have argued elsewhere:

an identity-constituting narrative is not, in and of itself, a good thing-much depends on the extent to which the identity is asserted or assigned ... When a person is able to fashion and project an identity-constituting narrative that she values (hopefully a self-narrative that fosters her talents and dreams) and is able to motivate appropriate uptake of the selfnarrative she embraces, there may be evidence of autonomy ... On the other hand, when a person is unable to contribute effectively to a satisfying self-narrative and finds herself forced to live within constraints set by others who have fixed ideas about who she is and who she can be, there may be evidence of oppression ([7], pp. 123-124).

When considered from a moral perspective, a person must be able to contribute actively to the authoring of her life in a manner that is consistent with her broader interests, values and commitments. When this is not the case, as when others have "a disproportionate hand in writing stories for [others] ... that are limiting, cruel, oppressive or alienating" ([24], p. 127), a serious moral problem arises because of the ways in which agency and autonomy are constrained. Consider, for example, the scope of possible identity-constituting narratives available to persons with PD (with or without DBS) in a society that is not welcoming of persons with physical and psychological disabilities. In such a society, a person's experiences will be significantly affected by stories others have constructed to restrict the range of narratives that can be appropriated and successfully enacted. In such a society, discriminatory attitudes towards persons with disabilities, not DBS for PD, would be a serious potential threat to personal identity. To be clear on this point, the threat to personal identity experienced by persons with disabilities is analogous to the threat experienced by women in a patriarchal society, by coloured people in a racist white society, and by gay people in a homophobic society. The threat, such as it is, are the beliefs and attitudes of others that result in stigmatization and alienation, which in turn may result in negative experiences and feelings being integrated into one's identity-constituting narrative.

A third response to the question "Is DBS for PD a threat to personal identity?" is similar in orientation to that offered by Schechtman. On a relational account of personal identity, "but for" the DBS the identity-constituting narrative would be quite different (perhaps even radically different). On this view, DBS for PD distorts the dialectical process of identity formation and, for this reason, is a threat to personal identity. DBS for PD limits how a person sees and understands herself; as such DBS limits what the protagonist of an autobiographical narrative can project for minimal endorsement by others. A person with PD who has been treated with DBS cannot successfully project a self-narrative that is impervious to the fact of DBS. This constraint on what can be projected, acts as a constraint on what can be perceived. In turn, the interplay between constrained projected and perceived self-narratives gives rise to a different identity-constituting narrative.

A problem with this perspective on DBS for PD as a threat to personal identity, however, is that it renders any and all life events and experiences (whether initially considered positive or negative) potential threats to identity. If DBS for PD is a threat to personal identity because it constrains how a person sees and understands herself, which in turn constrains the dialectical process of identity formation, then so too PD is a threat to personal identity, and so too is potentially every other life event or experience integrated into an identity-constituting narrative including graduation, promotion, job loss, marriage, birth of a child, tsunami, divorce, death of a loved one, earthquake and so on. As we live our lives (that is, as our story unfolds), we experience countless events that irrevocably constrain what narrative(s) we can project. For example, marriage following a brief passionate love affair does away with the identity of 
bachelor/bachelorette. Is this event/experience to be understood as a threat to personal identity? Does the answer to this question change if the partner turns out to be physically or psychologically abusive, or unfaithful, or obsequious? "But for" the marriage, the spouse might have more self-confidence, more independence, more friends, better health, and so on. Consider another example - onset of a severe neurodegenerative disease such as PD. For some this will be a devastating occurrence, for others this may prove to be 'the making of the man'. In either case the narrative flow will be disrupted.

Michael J. Fox was a prominent Canadian actor in the 1980s and 90s, well-known for his roles in the television series "Family Ties," and "Spin City" and in the "Back to the Future" movie franchise. In 1991, he was diagnosed with early onset PD. In 2000, a few years after having publicly announced his illness, he launched the Michael J. Fox Foundation for Parkinson's research. At this time, he also turned his attention to writing and has authored several bestsellers-Lucky Man (2002), Always Looking Up: The Adventures of an Incurable Optimist (2009), and A Funny Thing Happened on the Way to the Future, (2010). Michael J. Fox's identityconstituting narrative is complex and many of the narrative details are subject to multiple interpretations. At minimum, he is an accomplished actor, a published author, a person living with PD and an effective advocate for others living with PD.

To be sure, Michael J. Fox's life trajectory would have been very different "but for" his illness. It also would have been very different, however, "but for" his successful career as an actor. Moreover, without this prior successful career, he might not have become a successful advocate for people living with PD. And, without both of these life experiences he might not have been awarded the Order of Canada in 2011 for "a lifetime of outstanding achievement, dedication to the community and service to the nation." All of these events and experiences are part of his identityconstituting narrative; none of these events, each of which might be described as a biographical disruption, can properly be described as a threat to his identity.

To insist on this point, PD is to Michael J. Fox as spinal cord injury was to Christopher Reeve. The actor, famous for his role in the movie Superman (and sequels), was paralyzed as a result of an equestrian accident. Along with his wife Dana, he founded the Christopher and Dana Reeve Foundation to support spinal cord injury research and to improve the quality of life of persons living with spinal cord injury. Christopher Reeves' identity is that of the actorturned-advocate for spinal cord injury research. His accident was no more a threat to his personal identity (his autobiographical narrative) than his career as an actor. Both of these facets of his life were an integral part of his personal identity-his life story.

To recap, a major life event or experience that dramatically disrupts the narrative flow undeniably constrains the dialectical process of identity formation (and thereby alters a planned or anticipated narrative), but this biographical disruption does not, in itself, constitute a threat to identity.

A fourth plausible response to the question "Is DBS for PD a threat to personal identity?" suggests that DBS is such a threat but only insofar as it is a threat to agency - the ability to make informed and rational choices - as when a person's actions do not flow from her intentions or beliefs but rather are the result of direct brain manipulation. Here it is worth noting that following DBS patients not only report "I don't feel like myself anymore," and "I haven't found myself again after the operation," they also report "I feel like a robot," and "I feel like an electric doll" ([6], p. 1813). Emerging research on the effects of DBS on patients with PD suggests that there is cause for concern with respect to the ways in which direct brain stimulation potentially affects agency. For example, pathological gambling is now recognized as a potential side-effect of DBS [25-27]. This means that some patients with PD who have been treated with DBS and who spend excessive amounts of time in front of slot machines do not do so as a matter of choice, but as a consequence of brain manipulation. When direct brain manipulation explains a belief or behavior there is reason to think of this as a serious threat to agency, which in some instances may give rise to a threat to identity.

\section{Conclusion}

For illustrative purposes, this article has focused narrowly on DBS for PD. The conclusions that follow, however, apply to DBS in general.

DBS can be a uniquely disruptive experience resulting in dramatic changes in behaviour, mood and cognition. Such changes can have a major impact on personality and, according to some, can also have 
a major impact on personal identity. If personal identity is understood in static terms, it may be reasonable to worry about how changes in personality potentially threaten personal identity. But, if personal identity is understood in dynamic, narrative and relational terms (and if personality and personal identity are understood not to be synonymous), then the claim that DBS is a threat to personal identity is problematic. From one perspective, the claim is false because it misunderstands the dynamic nature of personal identity. From a second perspective, the claim is misdirected because it is not DBS for PD but rather the discriminatory attitudes of others towards persons with disability that are threatening to personal identity. From yet another perspective, the claim is trivially true as all dramatic events and experiences integrated into an autobiographical narrative, not only DBS for PD, are then potentially threatening to personal identity.

There is one sense, however, in which it may be accurate and not trivially true to describe DBS as a threat to personal identity. This is when DBS undermines agency to such an extent that the person is no longer able to meaningfully contribute to the authoring of her own life (i.e., to contribute to the cyclical and iterative process of projecting, defending and revising a self-narrative). Without the ability to contribute to the process of identity formation, a person loses the ability to hold on to a sense of self.

Acknowledgment Thanks are owed to Rob Brownstone Department of Surgery (Neurosurgery), Dalhousie University and Eliza Goddard, School of Philosophy, UTAS for comments on an earlier draft. The time and reflection needed to develop the relational account of personal identity relied upon in this article would not have been possible without the generous support of the Brocher Foundation, http://www.brocher.ch. In addition, this work is supported by the Canadian Institutes of Health Research NNF 80045, States of Mind: Emerging Issues in Neuroethics, and the Canada Research Chairs program (2004-2011).

Open Access This article is distributed under the terms of the Creative Commons Attribution Noncommercial License which permits any noncommercial use, distribution, and reproduction in any medium, provided the original author(s) and source are credited.

\section{References}

1. Glannon, W. 2009. Stimulating brains, altering minds. Journal of Medical Ethics 35: 289-292.
2. Merkel, R., S. Rosahl, B. Nuttin, et al. 2007. Ethical and legal aspects of neuromodulation: On the road to guidelines. Neuromodulation 10: 177-186.

3. Müller, S., and M. Christen. 2011. Deep brain stimulation in Parkinsonian patients-Ethical evaluation of cognitive, affective, and behavioral sequelae. AJOB Neuroscience 2 (1): 3-13.

4. Schechtman, M. 2009. Getting our stories straight: Self-narrative and personal identity. In Personal identity and fractured selves, ed. D.J.H. Mathews, H. Bok, and P.V. Rabins. Baltimore: Johns Hopkins University Press.

5. Schermer, M. 2011. Ethical issues in deep brain stimulation. Frontiers in Integrative Neuroscience 5: 17. doi:10.3389/fnint.2011.00017.

6. Schüpbach, M., M. Gargiulo, M.L. Welter, et al. 2006. Neurosurgery in Parkinson disease: A distressed mind in a repaired body? Neurology 66: 1811-1816.

7. Baylis, F. 2011. The self in situ: A relational account of personal identity. In Being relational: Reflections on relational theory and health law, ed. J. Downie and J.J. Llewellyn, 109-131. Vancouver: UBC Press.

8. Dubiel, H. 2006. Deep in the brain: Living with Parkinson's disease. Translated by Philip Schmidtz. New York: Europa Editions, 2009.

9. Medtronics AU. http://www.medtronicneuro.com.au/ ambassadors_richard.html accessed 20110822.

10. Medtronics US. http://www.medtronic.com/health-consumers/ parkinsons-disease/personal-stories/chris/index.htm accessed 20110822.

11. Leentjens, A.F., V. Visser-Vendewalle, Y. Temel, et al. 2004. Manipulation of mental competence: An ethical problem in a case of electrical stimulation of the subthalamic nucleus for severe Parkinson's disease. Ned Tijdschr Geneesk. 148: 1394-1398.

12. Johansson, V., M. Garwicz, M. Kanje, et al. 2011. Authenticity, depression, and deep brain stimulation. Frontiers in Integrative Neuroscience 5: 21. doi:10.3389/ fnint.2011.00021.

13. Schechtman, M. 1996. The constitution of selves. Ithaca: Cornell University Press.

14. Thomas, L.M. 1998. Moral deference. In Theorizing multiculturalism: A guide to the current debate, ed. C. Willet, 359-381. Oxford: Blackwell Publishers.

15. Sherwin, S. 1998. A relational approach to autonomy in health care. In The politics of women's health: Exploring agency and autonomy, eds. Feminist Health Care Research Network, S. Sherwin, coordinator. Philadelphia: Temple University Press.

16. Mackenzie, C. 2008. Introduction: Practical identity and narrative agency. In Practical identity and narrative agency, ed. C. Mackenzie and K. Atkins. New York: Routledge.

17. Mackenzie, C., and N. Stoljar (eds.). 2000. Relational autonomy: Feminist perspectives on autonomy, agency and the social self. Oxford: Oxford University Press.

18. Alcoff, L.M. 2006. Visible identities: Race, gender, and the self. Oxford: Oxford University Press.

19. Code, L. 1991. What can she know? Feminist theory and the construction of knowledge. Ithica: Cornell University Press.

20. Nelson, H.L. 2001. Damaged identities: Narrative repair. Ithica: Cornell University Press. 
21. Pimp your brain! 2009. http://www.pr.uni-freiburg.de/pm/ 2009/pm.2009-04-01.114/ accessed 20110822.

22. Schechtman, M. 2010. Philosophical reflections on narrative and deep brain stimulation. The Journal of Clinical Ethics 21: 135-141.

23. Gisquet, E. 2008. Cerebral implants and Parkinson's disease: A unique form of biographical disruption? Social Science and Medicine 67: 1847-1851.

24. Walker, M.U. 2007. Moral understandings: A feminist study in ethics. New York: Routledge.
25. Lu, C., A. Bharmal, and O. Suchowersky. 2006. Gambling and Parkinson disease. Archives of Neurology 63: 298.

26. Smeding, H.M.M., A.E. Goudriaan, E.M.J. Foncke, et al. 2007. Pathological gambling after bilateral subthalamic nucleus stimulation in Parkinson disease. Journal of Neurology, Neurosurgery, and Psychiatry 78: 517-519.

27. Hälbig, T.D., W. Tse, P.G. Frisina, et al. 2009. Subthalamic deep brain stimulation and impulse control in Parkinson's disease. European Journal of Neurology 16: 493-497. 